\title{
الابعاد الاجتماعية والنفسية للتهجير القسري على الاطفال في العراق
}

\section{م.م هديل تومان محمد البعاج / كلية الامام الكاظم (ع) اللعلوم الاسلامية الجامعة .واسط

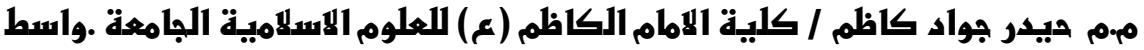

\author{
الخلاهة \\ ان تعرض المجتمع العراقي الى ازمـات عديدة نتيجة الحصـار الاقتصـادي لحوالي ( rاسنة ) ومـا لحق نلك من

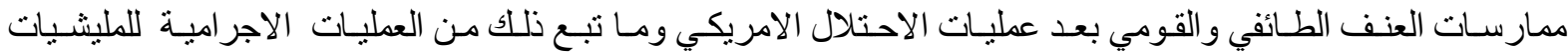

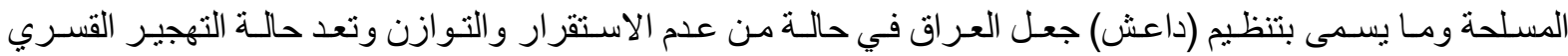 \\ الفردي و الجماعي الخارجي والداخلي هي من اهم مظـاهر عدم التوازن التي مر بها المجتمع العر اقي خصوصـا وان هذه

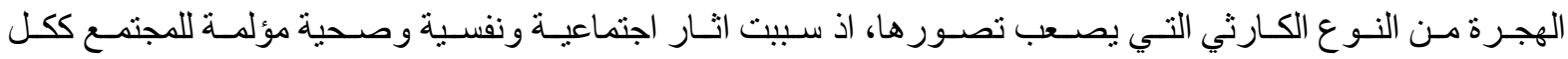 \\ وللمهجرين بصورة خاصة. وقد تناول هذا البحث مشكلة التهجير القسري في العراق و انعكاس هذه المشكلة على الحالة

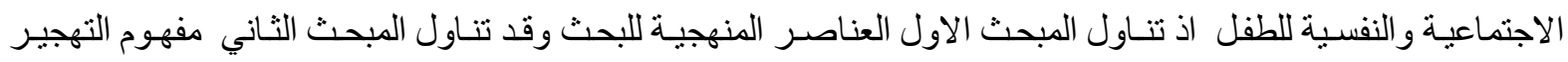

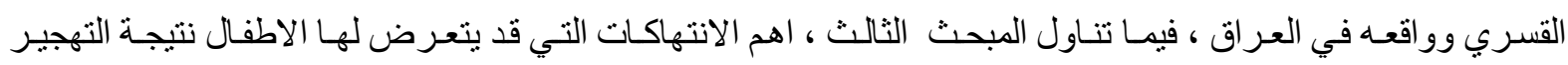

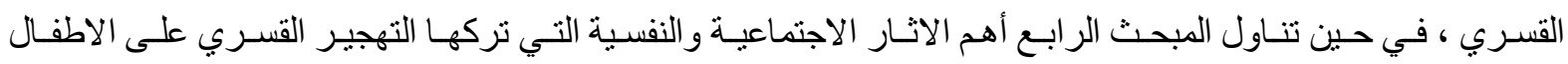

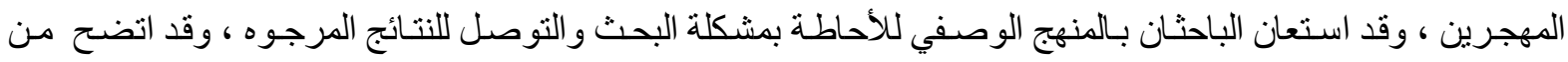 \\ خلال البحث اهم و اخطر الاضطر ابات الاجتماعية والنفسية وصعوبات العبش التي يعانيها الاطفال المهجرين ومـا يمكن

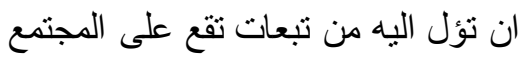

Abstract

The Iraqi society faces many crises as a result of the economic blockade around 12 years and followed with violence and national sectarian after the US occupation. Also, there were criminal operations and gangs like ISIS (Dash) make Iraq in a state of instability, balance, and the forced displacement of individual and collective external and internal security is one of the most important manifestations of the imbalance which the Iraqi society has faced, especially this migration is from the catastrophic type that is unimaginable, caused the effects of psychological and social health for the community as a whole and displacement people in particular way. This study deals with the problem of forced displacement in Iraq, and the reflection of this problem on the social and psychological situation of the child. The first part contains the methodology of study. The second part tells us about the concept of forced displacement and its situation in Iraq, while the third part deals with the most important violations to which children may be faced as a result of forced displacement. the Fourth part tells us the most important social and psychological effects left by the forced displacement of the displaced children, the two researchers used a descriptive approach to capture the problem of the study and reach the desired results, it is clear from this study the most important dangerous social disorders and psychological difficulties of living experienced by the displaced children and what could be construed by the consequences of the fall on Societ

المقدهة

تعد الهجرة - لاسيما الهجرة القسرية - ظـاهرة خطيرة اخذت تقلق المجتمع، فهي ليست خطيرة على المهجرين انفسهم وحسب، بـل اخذت خطورنها تطـال حيـاة المجتمع ككل، بصفتها متغير ثقافي رئبس في المجتمع العر اقي، وقد تز ايلت أعداد المهجرين قسر ا ـ داخليا وخارجيـا - بسبب الكوارث الانسـانية، والطائفيـة، والسياسية، واستمر ار اعمـال العنف في منـاطق النز اع مثل الموصل، و الرمـادي، وديـالى، وتكريت، وغيرهـا من المنـاطق التي طالتهـا يد الارهـاب 
الداعشي، مما سبب في تز ايد اعداد المهرين قسرا، وازدادت تحديات الازمـة السياسية، والاقتصـادية، والاجتماعية على المجتمع. وتتضح تجليات هذه الازمة بصورة كبيرة على الاطفال الذين هم بذرة الانسـانية ، اذ ان هنالك نسبة كبيرة من

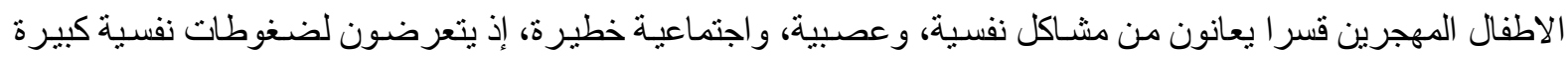

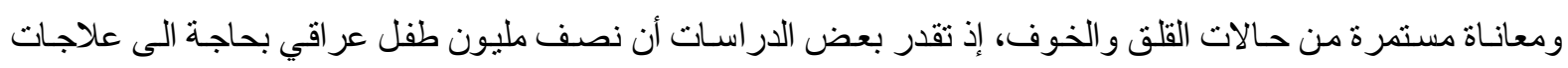

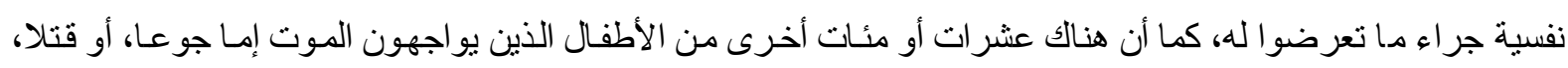

$$
\text { أو جر اء الامر اض والأوبة التي انتشرت في الآونة الهنة الأخيرة. }
$$

ونظر الخطورة هذه المشكلة وتداعياتها الاجتماعيـة والنفسية على الطفل العر اقي عزم الباحثنان على تحشيد

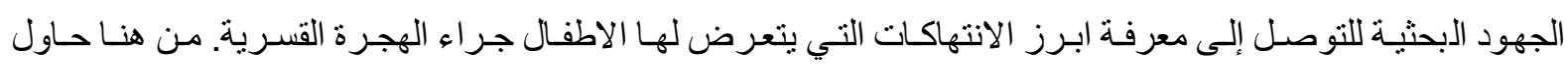

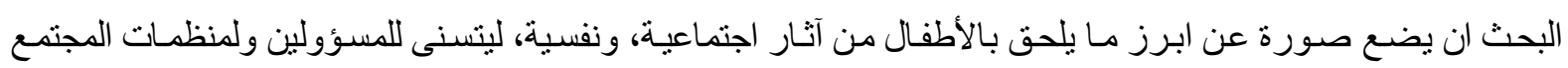

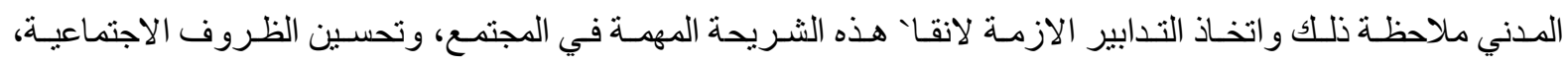
و الصحية، والنفسية، التي كانت السبب الرئيس في انتهاك الأطفـال و ايصـالهم الى هذه الحالـة التي حرمتهم من طفولتهم و ابسط حقوقهم في العيش .

\section{المبحث الاول : العناصر المنهمية للبحث}

أولا: مشكلة البحث :

في البدء لا بد من الاشـارة الى مفهوم المشكلة كي ينسنى لنـا تحديد تداعياتها واسبابها، وهي بصورة مـوجزة

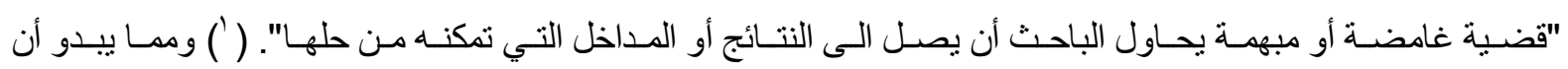
التغيرات الكثيرة التي يشهرها المجتمع العر اقي في تاريخه المعاصر كان لها أثر فعال في ظهور العديد من المشكلات في مضـامينها وتجلياتها، ولعل أبرز المشـكل الحديثة اليوم هي التهجير القسري وانعكاس هذه المشكلة سلبا على الاطفـال،

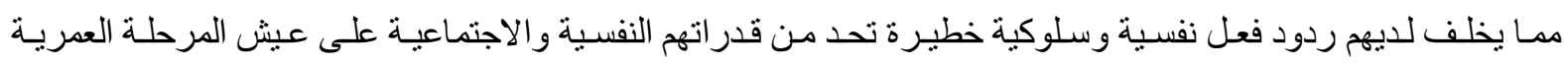

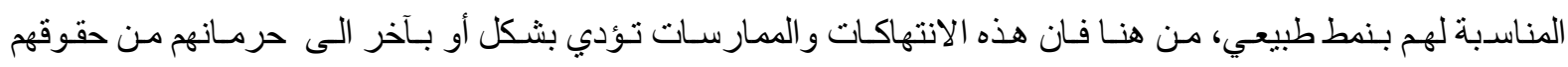
المشروعة .

ثنانيا: اهمية البحث :

تكمن اهمية هذا البحث في محورين اساسيين، هما المحور العلمي وهو المحور الاول، والآخر المحور المجتمي.

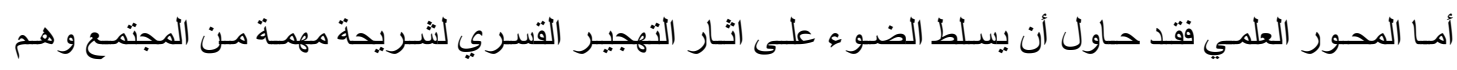

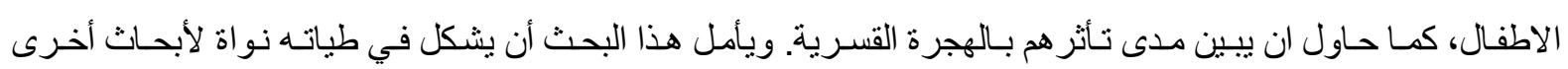

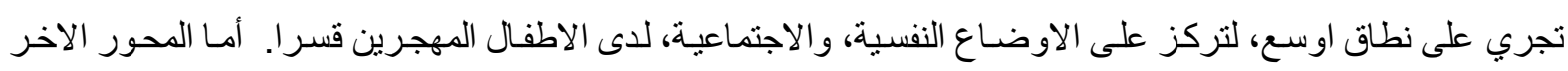

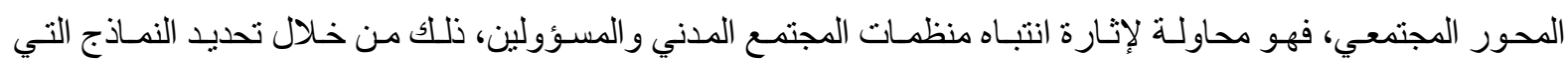
توضح لهم رؤية سليمة للواقع السلبي بهذف بناء برامج علاجية في التخلص من الاثار المدمرة لمستقبل الطفل العراقي . ثالثا : الهداف البحث:

يسعى هذا البحث من خلال الاجراءات المنهجية والنظرية الى تحقيق الأهداف الآتية

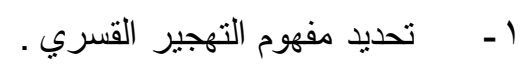

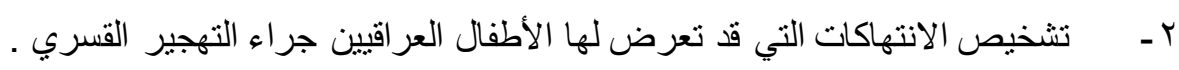


r - معرفة الآثار النفسية والاجتماعية التي تولدت عند الطفل نتيجة التهجير القسري .

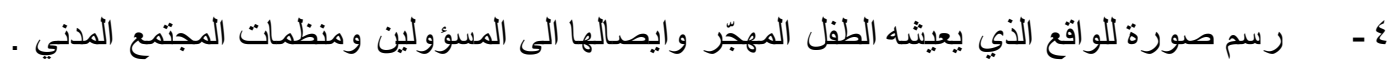
رابعا : المنهج المستخدم في البحث:

يعتمد الباحثان في هذا البحث على المنهج الوصفي بصفته اكثر المنـاهج عطـاء في هذا المجـال، فضـلا عن كونـهـ

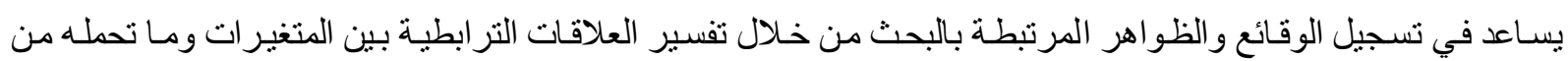
تغيرات سلوكية في افكار الجمهور للوصول الى اسباب الظواهر والعوامل التي تتحكم فيها، واستخلاص النتائج من خـلال

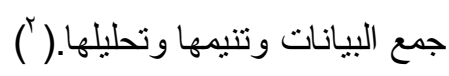

\section{المبثث الثاني : هفهوم الهجرة القسرية وابرز خصائصها :}

عرفت الأمم المتحدة مفهوم الهجـرة انهـا شكل من اشكال الانتقـال الجغر افي و المكـاني المتضـمن التغيير الـائم

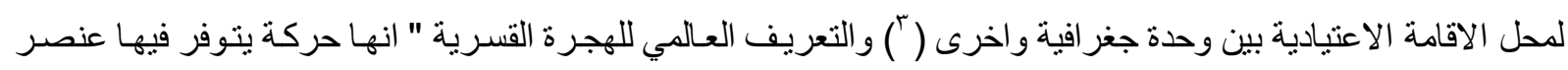

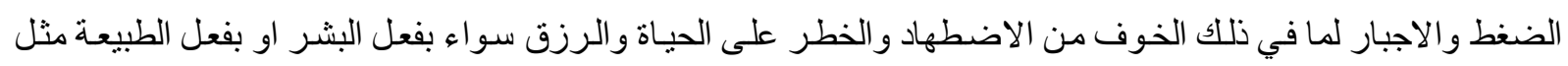

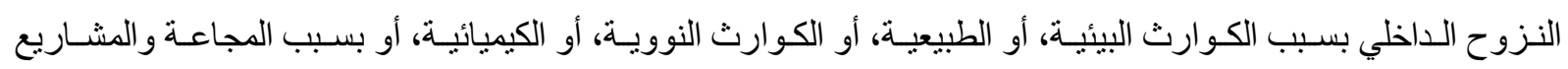

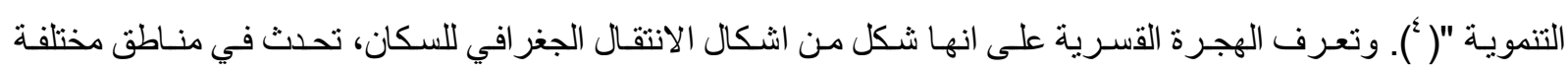

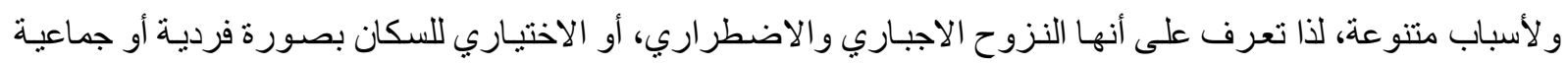

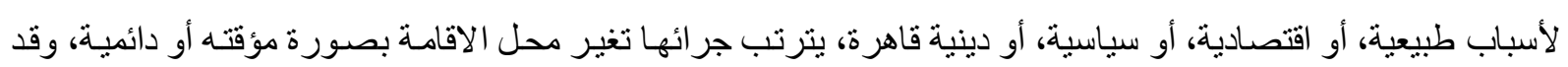
تتم بصورة مباغتة بدفعة واحدة أو على شكل دفعات ( (0). ومن ابرز خصائص الهجرة القسرية :

ا - تكون على شكل تيارات منقابلة تأخذ اتجاهات عكسية ( مناطق طاردة تجنب في نفس الوقت نازحين اخرين ).

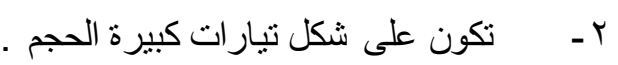

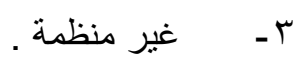

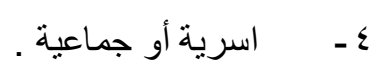

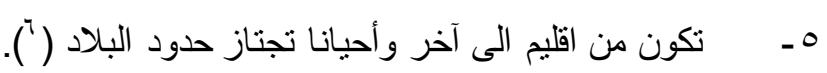

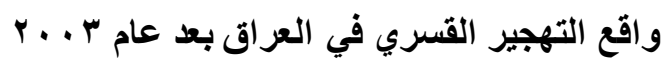

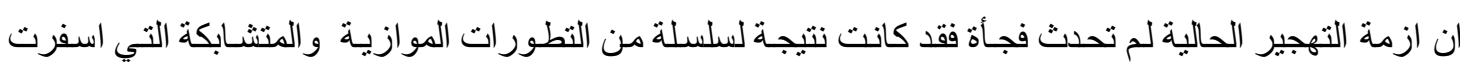
عن حجم التهجير الهائلـ الغير متوقع بعدة سيطرة داعش على مايصل الـى ثلـث الار اضـي العر اقيـة وموجـات التهجيـر

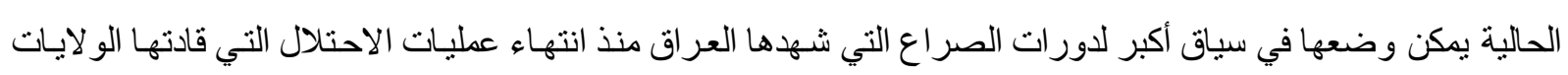

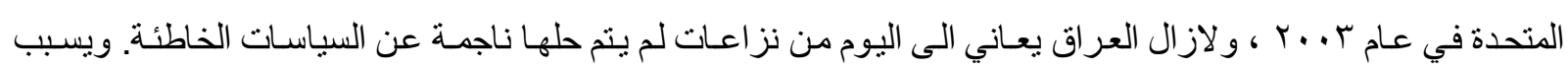

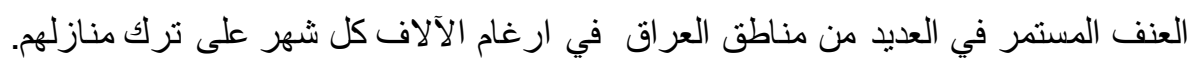
وقد كـان هنـاك أمل بعد التدخل العسكري الذي حدث في مـارس عـام ب . . ب أن يعود عدد كبير مـن المهجرين

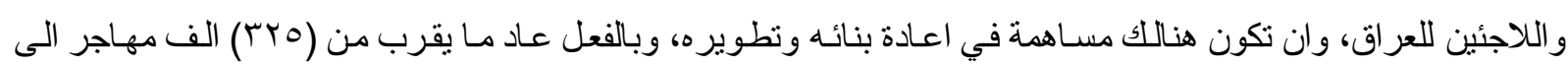

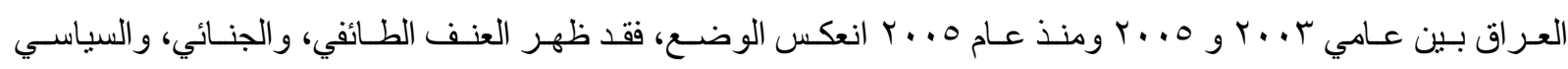

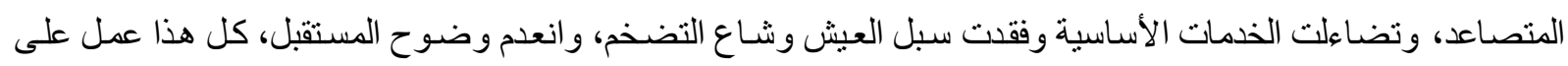


احباط عزيمة الكثير من العر اقيين ممن كانوا يرومون العودة، ودفع مئسات الآلاف منهم الى الهجرة داخل العراق وخارجهـ واصبحت هجرة العر اقيين اكثر عملية هجرة قسرية يشهدها تاريخ الشرق الاوسط. وتقدر مفوضية الامم المتحدة لثؤون اللاجئين أن هناك مـا يقارب من 9, أليون عراقي نـاز ح داخليا، و اكثر من

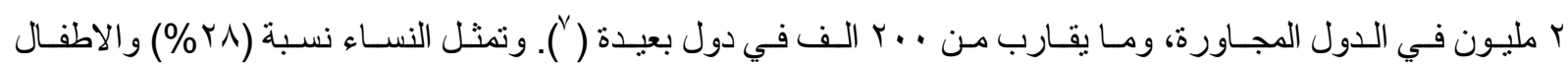

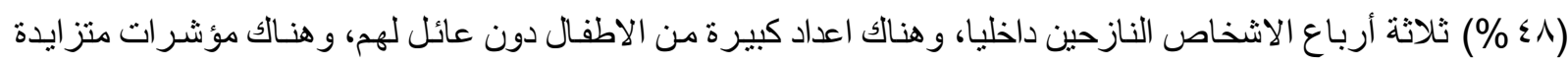

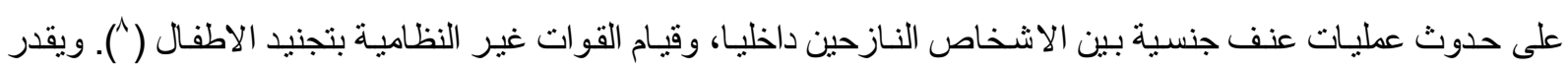

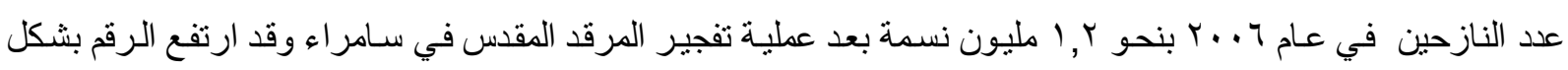

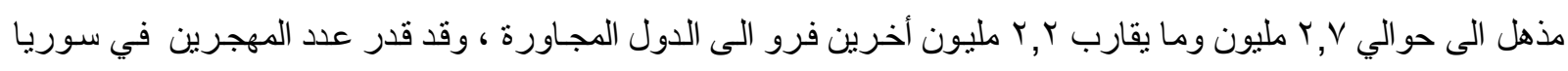

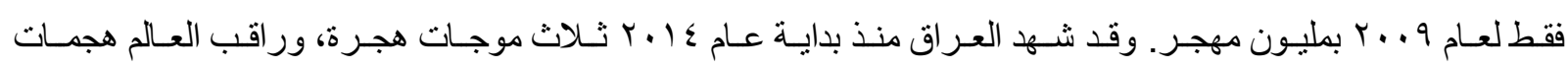

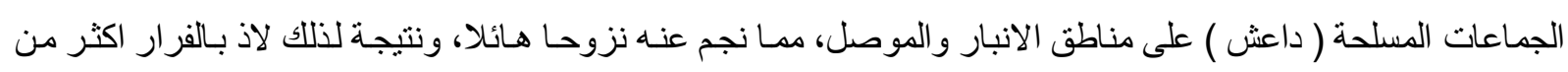
r مليون عراقي جر اء العنف والنزاع المسلح.

كما أن العديد من الذين فروا بـأرواحهم وجدوا انفسهم دون مـأوى، وهم r مليون نـاز ح عراقي من الداخل، اضـافة

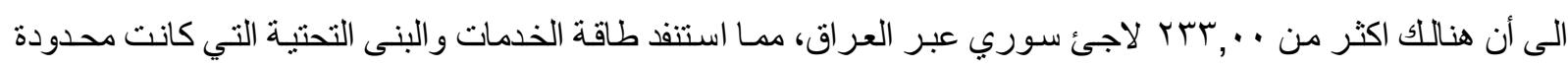

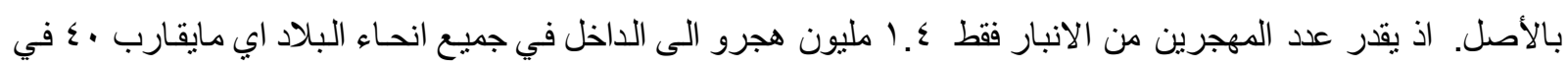

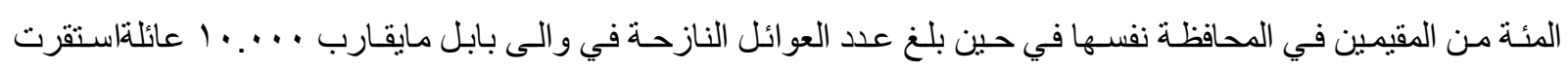

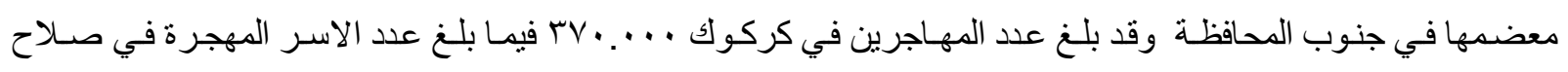

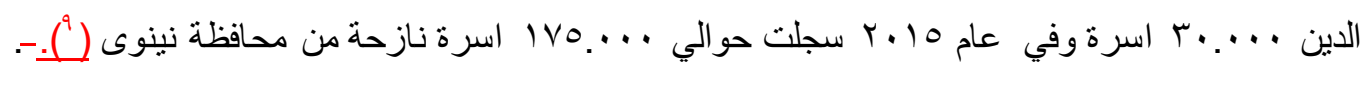

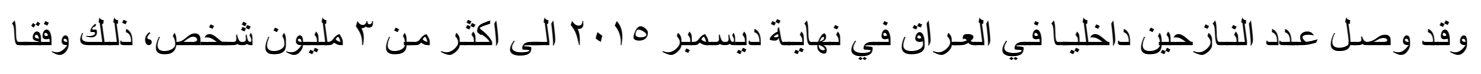

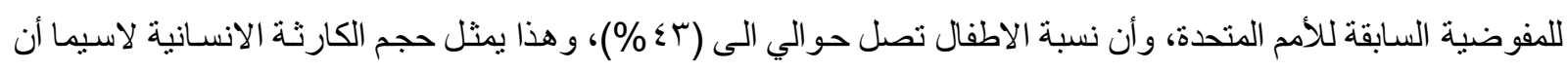

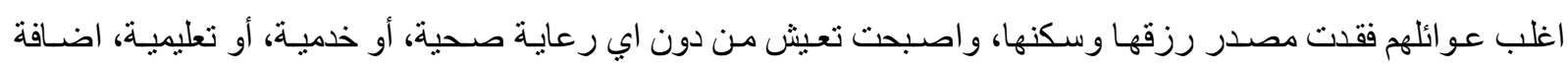

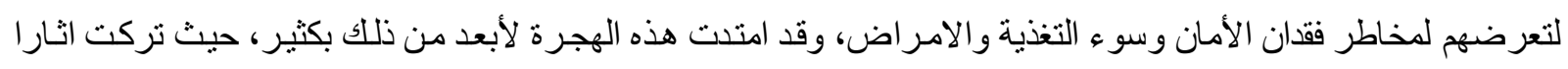

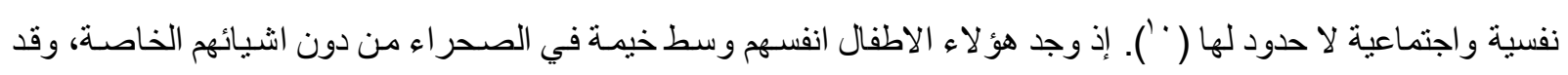

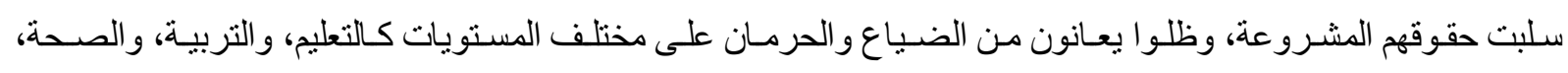

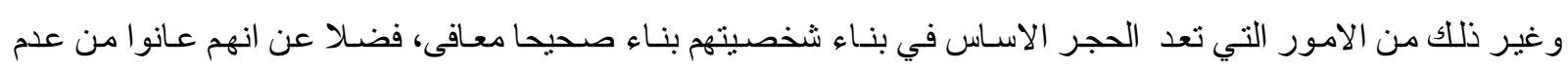

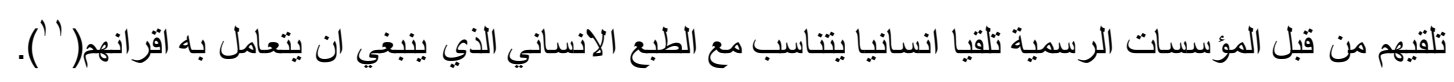
وتتز ايد مع الايسام اعداد الاطفـال النـازحين داخل العراق وخارجه، وينتج عن هذا النزوح انفصـال الاطفال عن

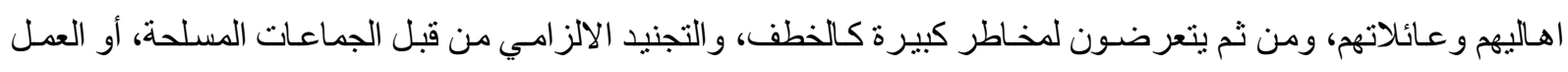

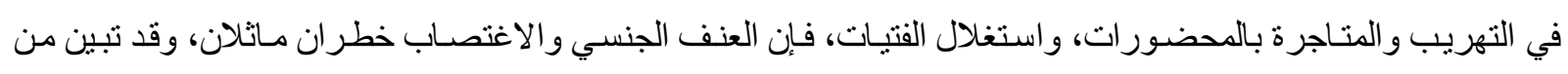

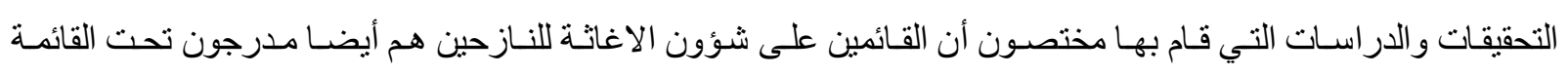

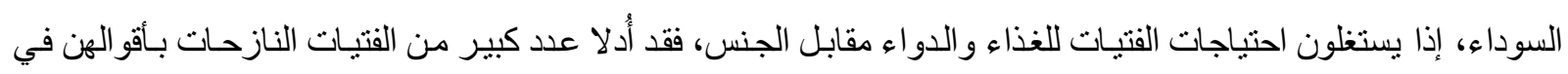

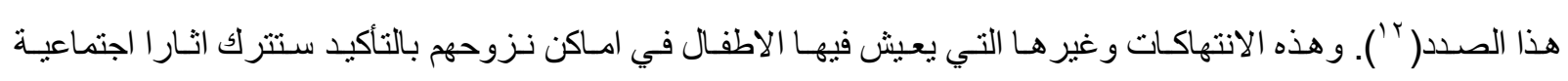

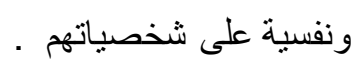




\section{المبمث الثالث :-الانتهاكات التي يتعرض لها الاطفال جراء التهبير القسري :}

تشكل الانتهاكـات الموجـه ضـــ الاطفـال المهجرين قسـر افي العـراق محسورا اسـاسيا مـن المحساور الجسيمة، اذ استمرت انتهاكـات الاطفال في العراق بشكل مطرد، إذ تم تعذيب الاطفـال واعتقالهم واجبـار هم على ادلاء شـهادات تحت التعذيب، وحرمانهم من حق التعليم وحقوق الصحة والعيش الكريم. وسـنعرض هنـا ابرز الانتهاكـات التي تعرض لها الاطفـال في العـراق منذ بدـء عمليـات التهجير القسري التـي انتهنتها الميليشيات المسلحة وهي تشكل جز ء لهذه الانتهاكات.

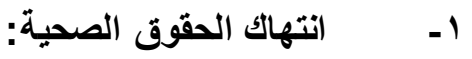

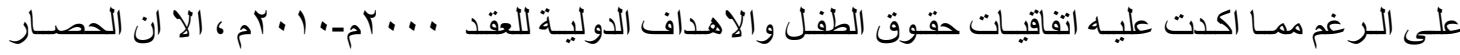
المفروض على العراق و الحروب و الازمـات والهجرة القسرية الداخلية التي لم يشهـ العـالم منلها والتي تلت الحصـار لهـا الاثر الكبير في انتهاك حقوق الطفل، ممـا ادى الى تفاقم الازمـات الصحية وازديـاد اعداد الوفيـات والامر اض السرطانية و الو لادات المشوهة والامر اض الانتقالية و التلوث البيئي الخطير وامراض سوء التغذية اذ تثير الاحصـائيات الى انه منذ

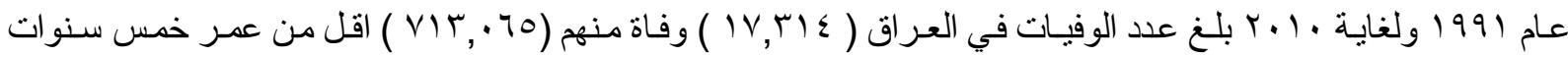

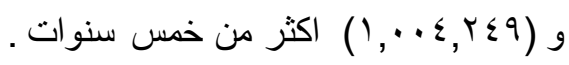

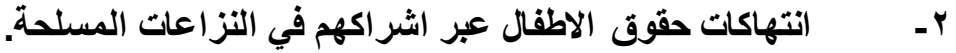

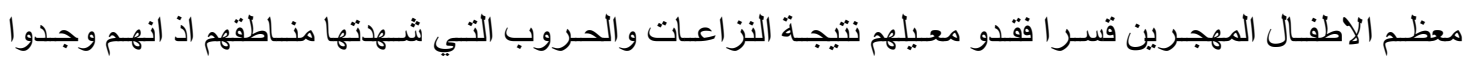

انفسـهم فجـاة دون عائلـة ودون مصدر للحنـان و العطف ممـا جعلهم لقمـة سـائغة للتغريـر بهم أو خطفهم وتجنيدهم مـن قبـل الجماعات المسلحة. وقد اشـارت الاحصـائيات الى أن مـا يقرب من (

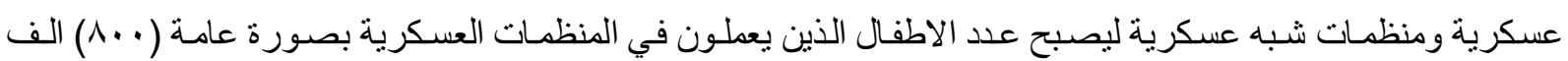
طفل. وتضـيف الاحصـائيات أن مشكلة التجنيد او اشـر اكهم في العمليـات العسكرية اصبحت ظـاهرة عالميـة كمـا أن هنـاك

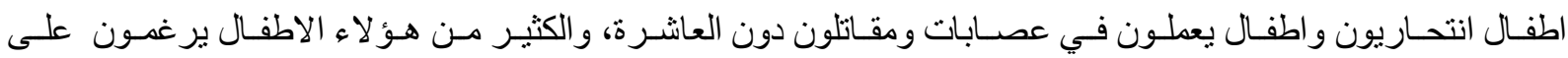
الاشتر اك في قتل افر اد اسر هم لكي يتعلموا الجلدة والقسوة ويصبحون مقاتلين اشداء حسب زعمهم، وفي كثير من الاحيان

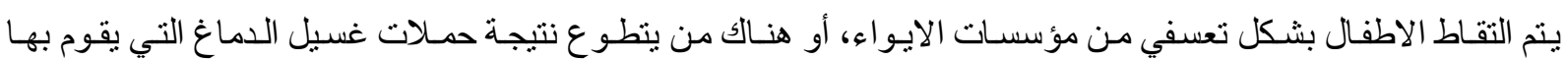

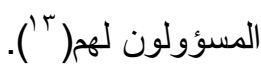

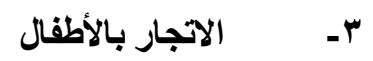
ويعد الاتجـار بالبشـر عمل اجرامي، وتحدي عـالمي، وقد اصبح في متنـاول عصـابات تجـارة البشـر في العراق فرصـة ذهبيـة للحصول على اربـاح كبيرة من خـلال المتاجرة بالنـازحين واللاجئين الاطفـال مستغلين الوضع الامني غير

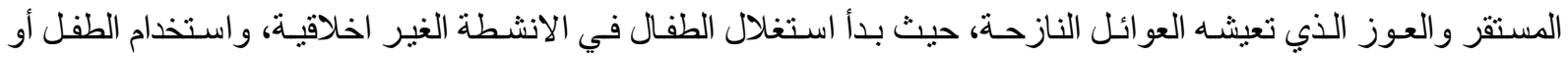

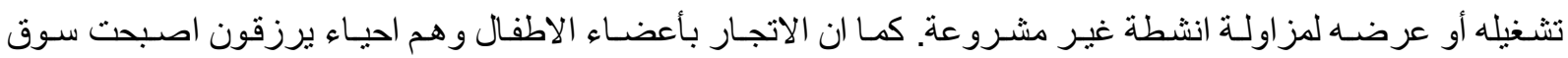
سوداء خاصة وخفية جدا لأنها غير شرعية لا سيما اذ مـا كانت بغير ار ادة صساحبها، أو رافقتها عمليات خطف خاصـة لا لا تهدف الى الابنزاز وكسب مـال المخطوف أو العائلة، بل على اقتطلاع عضو حي من جسم المخطوف لبيعه على شخص آخر يحتاج اليه ، كونه قادرا ماديا انها تجارة سوداء في الاعضاء البشرية . 


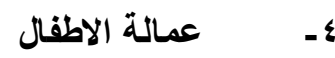

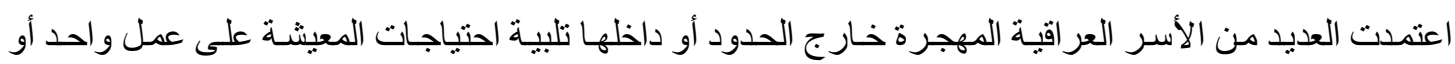

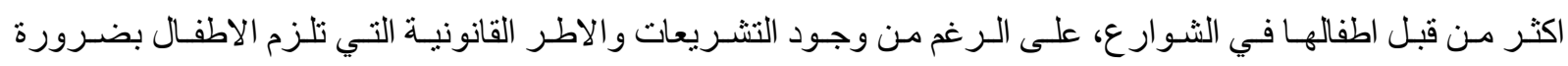

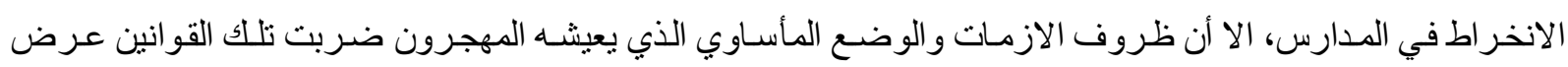

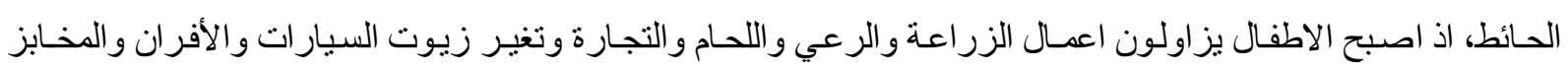
و التجول لبيع الصحف و السلع وقطع الحلوى وتلميع الاحذية وغيرها. لتحصيل لقمة العيش البسيط لعوائلهم ( ('). هـ الاتتهاكات النفسية والاجتماعية من ابرز مظاهر الانتهاكات النفسية والاجتماعية

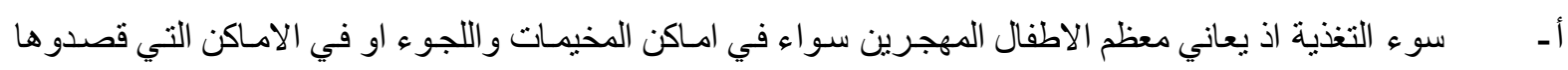

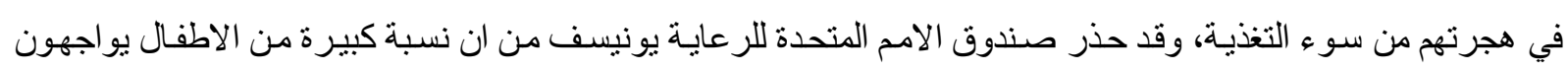
الموت بسبب سوء التغذية ب- اطفال الثوارع والايتام : تضخم عدد الأيتام في العراق مماز زاد وضعهم سوء.

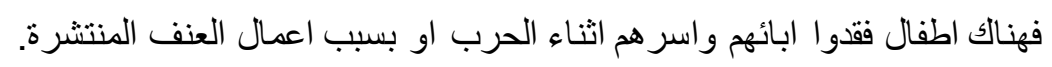

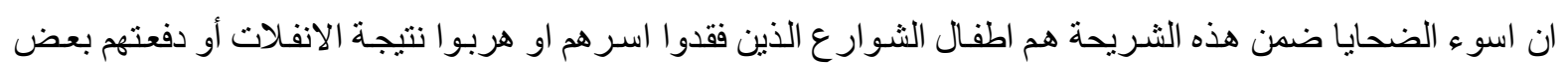

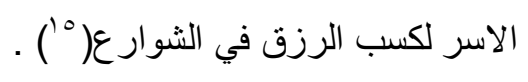

\section{المبمث الرابع :الابعاد الاجتماعية والنففية المتزبة على الطفل المهجير}

في العراق توسعت مصادر العنف ضد الاطفال، حيث يعيش وطنتـا متغيرات امنية، واجتماعية، وسياسية حسادة،

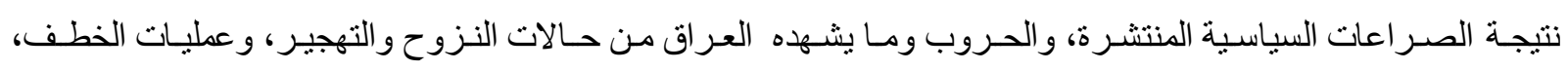

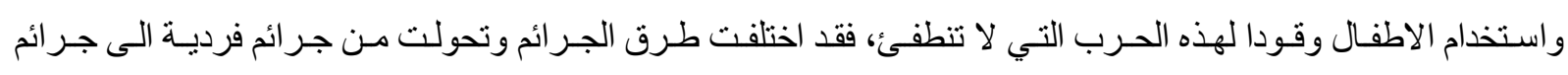

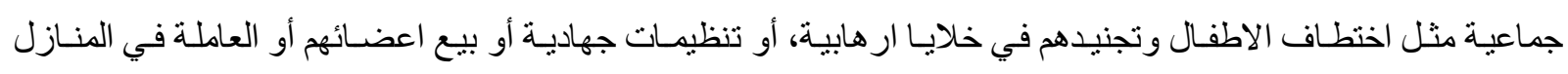

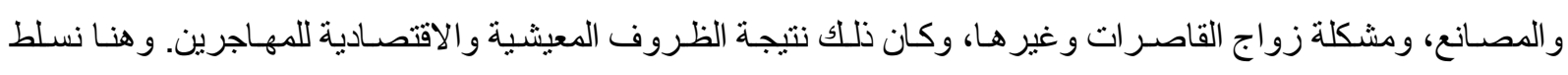

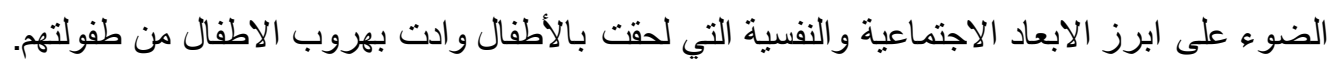

اولا: الابعاد الاجتماعية.

تباين معدلات النمو السكاني بين المحافظات تكمن خطورة الهجرة القسرية في العر اق بأنها حصلت في فترة

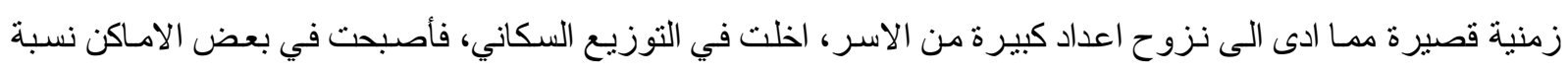

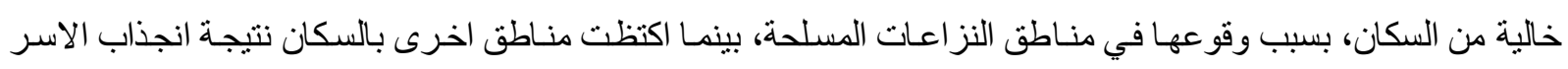

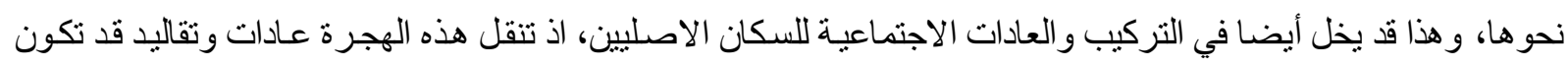

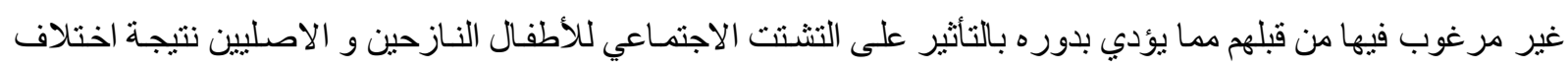
القيم و المعاير . مغير

1 - الضغط على الخدمات: ان اغلب محافظات العراق كانت تعاني مسبقا من تردي واضح في مستويات الخدمات

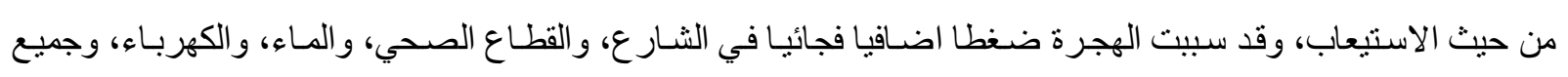


القطاعات الاخرى، وقد الحق ضرر المستوى كفاءته و ادائه لمجموع المستقبدين، وحرمـان الكثير من الاطفـال من الرعاية الصحية والالتحاق بالمدارس.

r - - تزايد العشوائيات: اجبرت معظم الاسر المهجرة قسرا على السكن في السـاحات الخالية، ممـا ترتب علية ظهور العشو ائيات، وهذا ادى الى الاخلال بمعايير السكن الحضاري الملائم .

r- - التفكك الاجتماعي وضعف الروابط الاجتماعية: يظهر التفكك الاجتماعي عندما يحلث اضطر اب نتيجة الهجرة أو الحروب و الكوارث، و هذا يؤدي الى حالات من التصادم في القيم والمثل الاجتماعية.

وقد عمدت المجاميع المسلحة الى اثار الفتنـة الطائفيـة بين ابنـاء المجتمع ممـا يؤدي الى تمزيق النسيج الاجتمـاعي وضـف الروابط والعلاقات الاجنماعية.

ـ - انتشار ظاهرة التسول و التسرب من المدارس نتيجة تدهور الوضع الاقتصسادي، وتحديدا عند العوائل التي فقدت

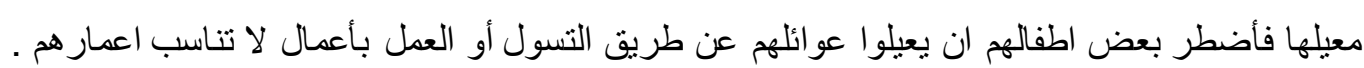
ه - البطالة : حيث افرزت الهجرة القسرية ظـاهرة البطالـة بشكل كبير ، اذ اجبرت العديد من العوائل التي تركت

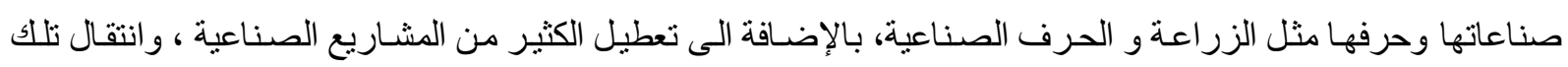
العو ائل الى اماكن جديدة تاركين عملهم .

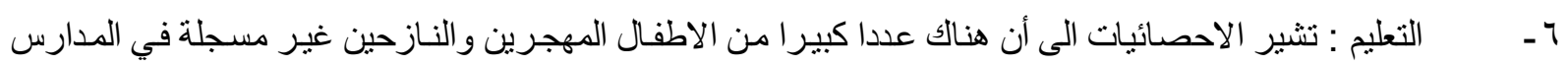

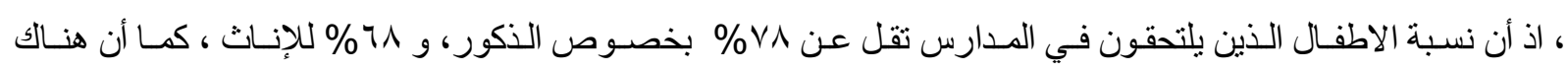

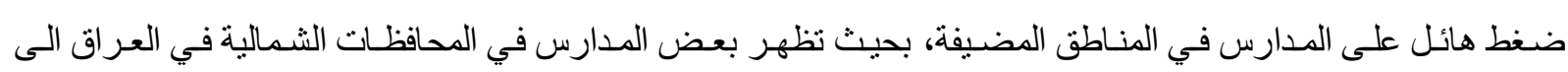

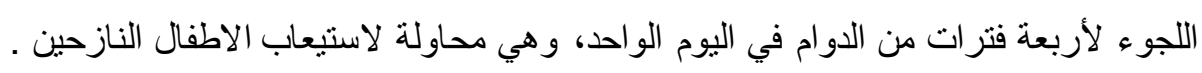
كما تم تطبيق نظام تعدد الدوام اليومي في المدارس المضيفة ، وييدو أن الفقر والوضع القانوني غير المحدد هو من ابرز

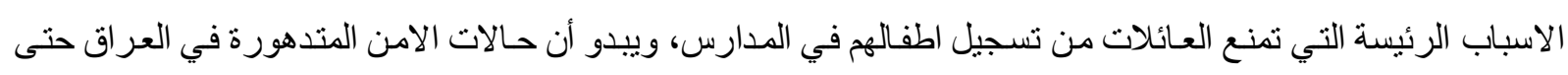

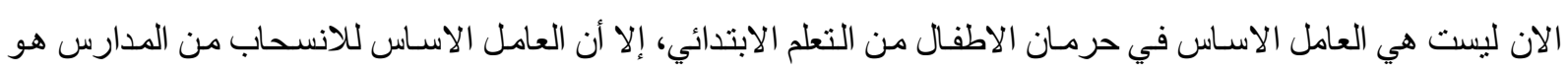

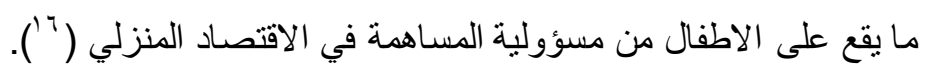
ثانيا: الاثار النفسية

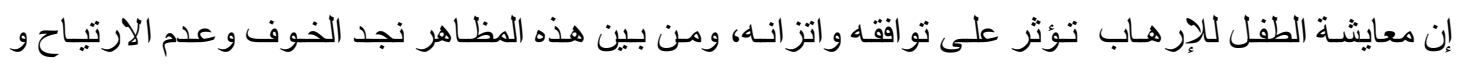

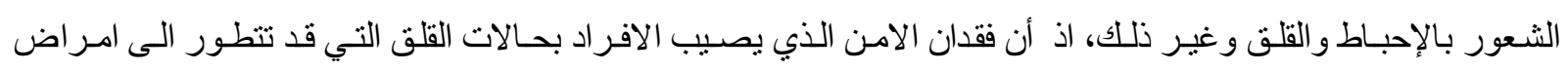

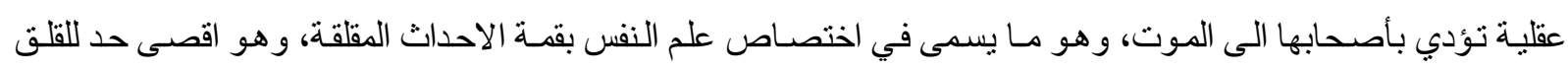
الذي من شأنه أن يذهب بعقل صاحبه، كأن تتعرض عائلة الطفل الى ابادة جماعية من طرف فئ جماعة ارهابية وينجو الطفل من الابادة، فيتعرض لازمات نفسية مختلفة، وقد يتطور الحال الى مشـاكل نفسية مختلفة وهذا مـاو واجهه العديد من الاطفيهال

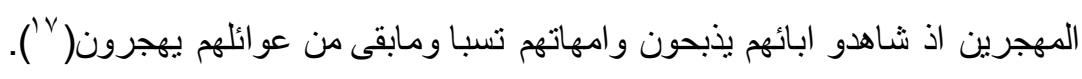
ك- كذللك يعـاني الطفل من حسالات نفسية صعبة نتيجة مـا يرى من هدم بيت الاسـرة، و المدرسـة، وسـاحة لعب الاطفـال،

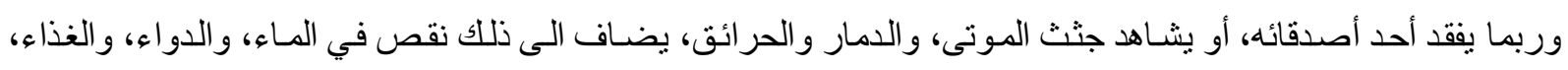

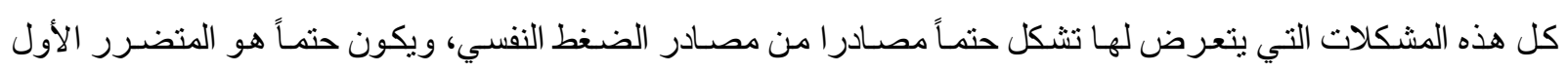


فيها، لأن ضغوطاً نفسية من هذا النوع تؤثر على مستقبل الطفل وصحته ومستقبله الدراسي، وذللك لمـا تحمله هذه الضغوط من ردود افعال سلبية مؤلمة (1^).

r - ويتضح أن التهجير، و النزوح، والنزاعات السياسية، والمسلحة، تترك آثنار اً مدمرة في شخصية الطفل، وتتمثل هذه

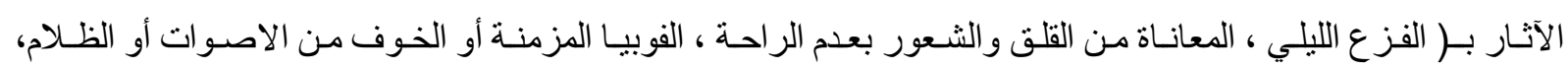

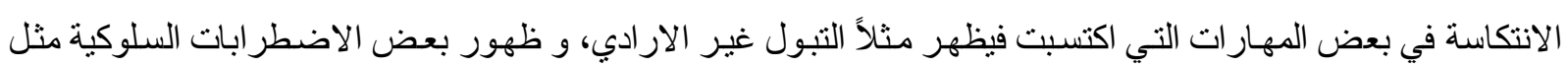

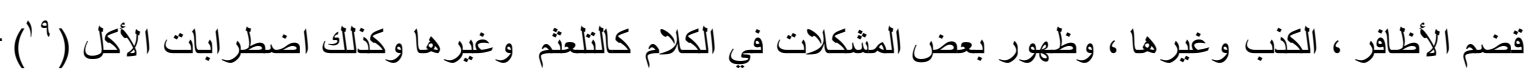

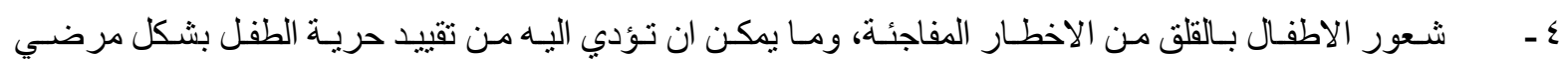

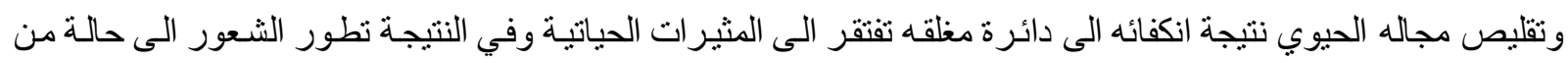
الياس المزمن و العجز و الاحباط المستديم .

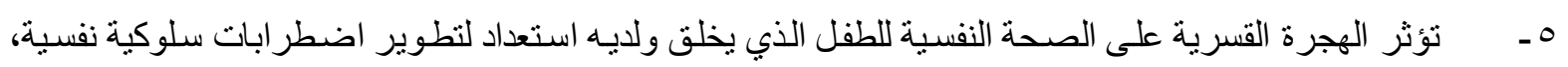

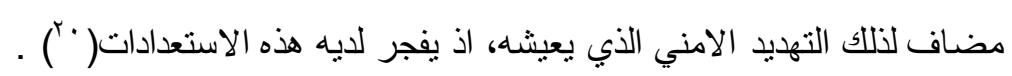

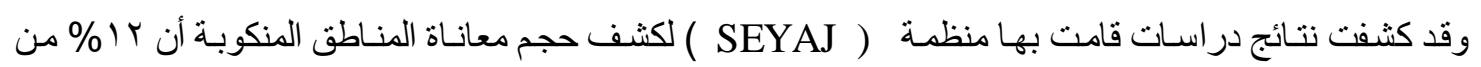
الاطفال يعانون من العزلة و الانطواء، وهي نسبة كبيرة مقارنة بمـا يجب أن يكون عليه الاطفال بالحالـة الطبيعية، كما وقد

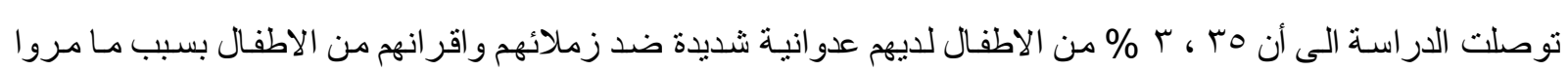

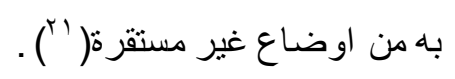

\section{النتائج}

ا. تداعيات اثر الهجرة القسرية انصب بشكل ملحوظ على الاطفال بدلالة العنف و انتهاكات حقوقهم والاختطاف. r. التنشئة الاجتماعية السليمة لها دور في حياة الطفل وهذا مـالم يتـوفر في ظل الظروف المتأزمـة التي يعيشـهل الاطفال المهاجرين في العراق r. سوء التغذية والأوبئة التي ادت الى ارتفاع نسب الوفيات بين الاطفال المهجرين ع. احتضن الثـار ع الاطفـال المهجرين من اجل ضـمان فرص العيش وهذا انعكس بشكل ملحوظ على معدلات التحاقهم بالمدارس و التعليم

○. عدم تحمل السلطات العر اقية ندابير شاملة لدعم المهاجرين او محاولة اعادة دمجهم اوتوفير اماكن لأيو ائهم

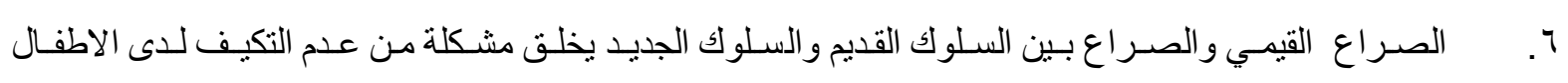
المهجرين

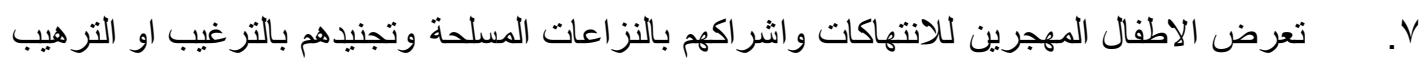
التوصيات : ا - العمل على تفعيل قانون التعليم الإلزامي في العراق واخذ الإجراءات الازمة لتعيده .

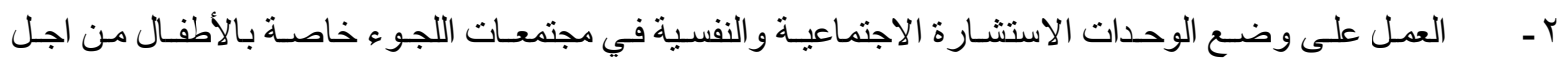
مساعدة الطفل و الحفاظ على الطفولة السلمية . 
ب - توفير المساعدات المادية و الغذائية الازمة للأطفال المهجرين بمساعدة وزارة التجارة ومنظمات المجتمع المدني ع - تفعيل قو انين لغرض العقوبة الثديدة على الجناة والمنتهكين لحقوق الاطفال المهجرين .

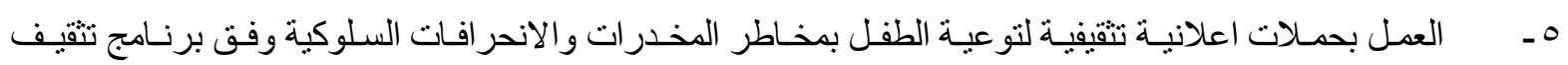
الاطفال المهرين .

7 - معاملة الاطفال المهرين كضحية تستحق الرعاية والاهتمام ومحاولة ادماجهم من جديد في المجتمع .

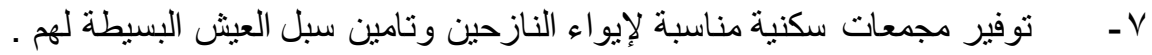

\section{هواهش البحث}

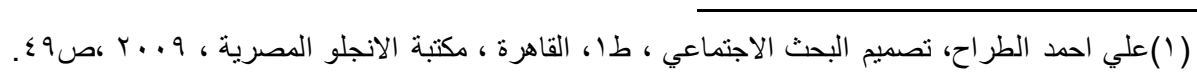

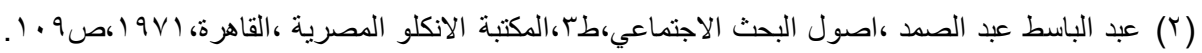

United Nations ,multiling demqrphic dicbionary 1958,p 76. ( $(\Gamma)$

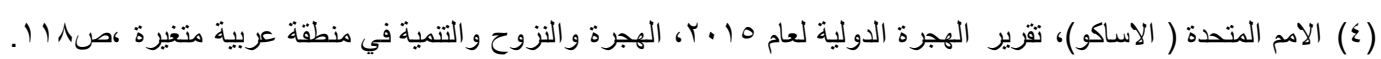

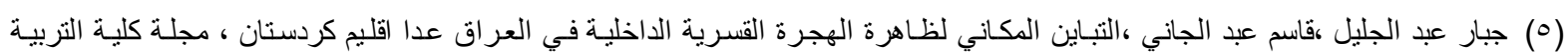

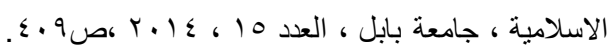

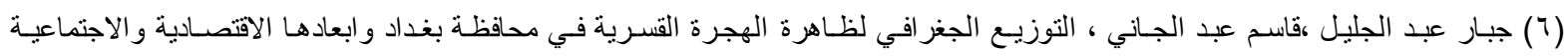

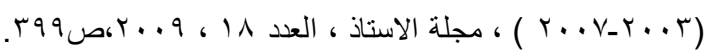

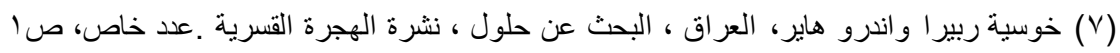

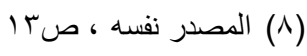

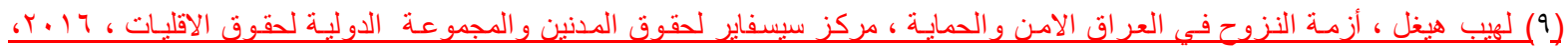

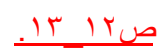

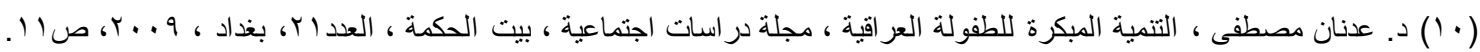

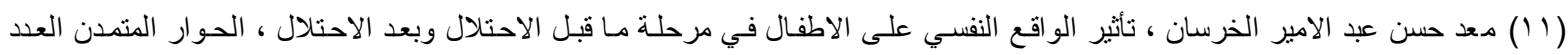

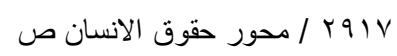

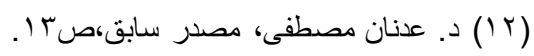

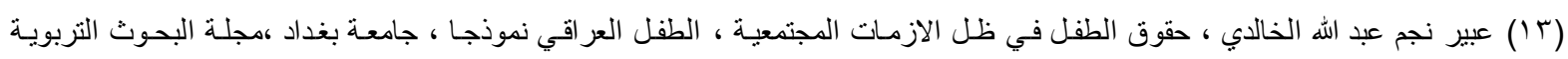

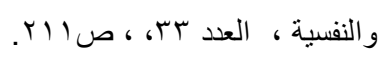

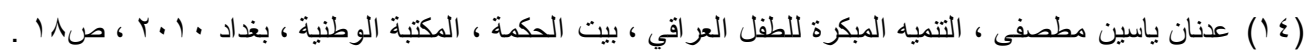

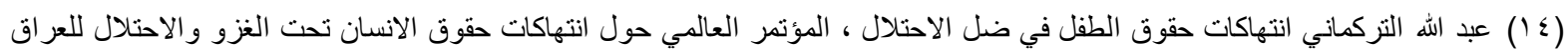

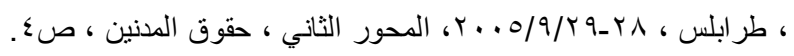

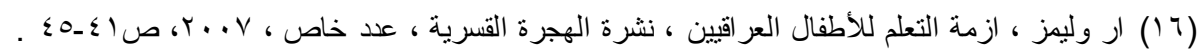

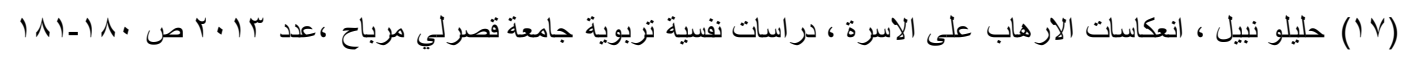

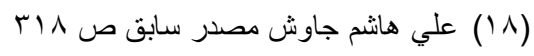

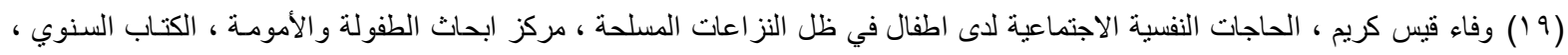

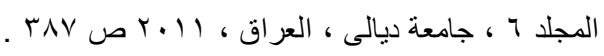

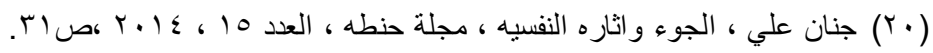

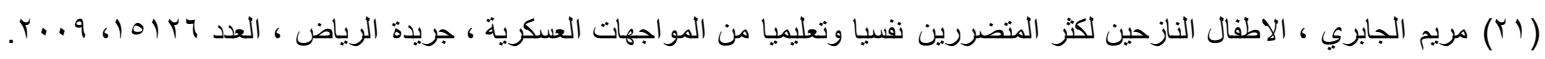




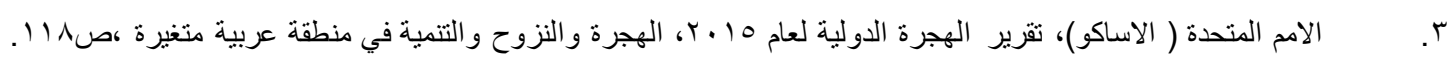

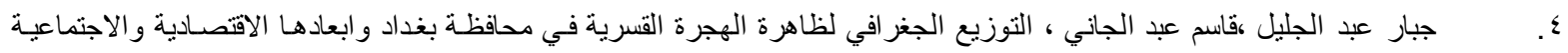

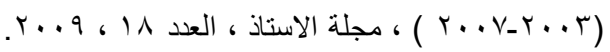

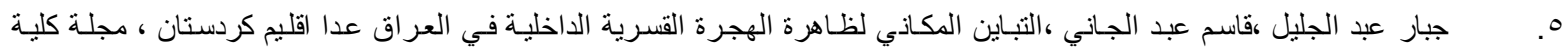

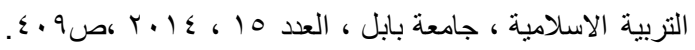

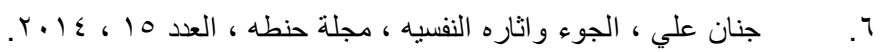

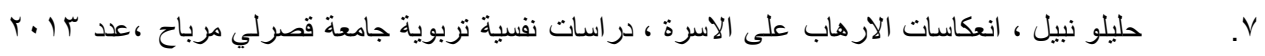

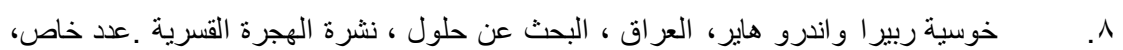

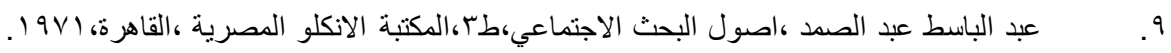
• ا. عبد الله التركماني انتهاكات حقوق الطفل في ضل الاحتلال ، المؤتمر العالمي حول انتهاكات حقوق الانسـان تحت الغزو والاحتلال

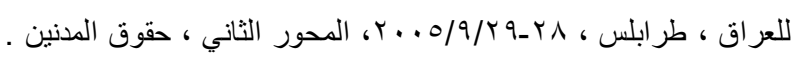

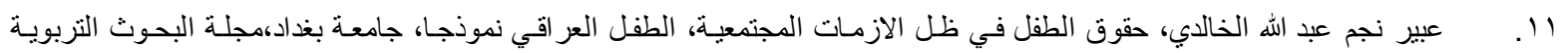
و النفسية ، العدد سب.

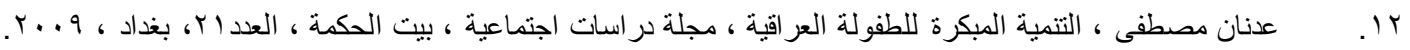

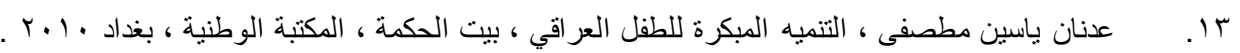

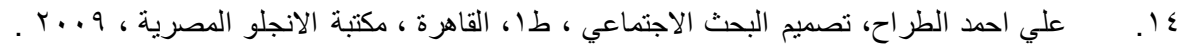

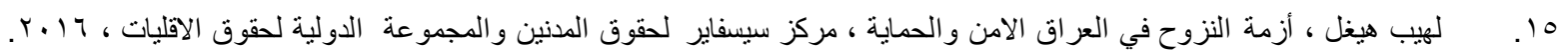

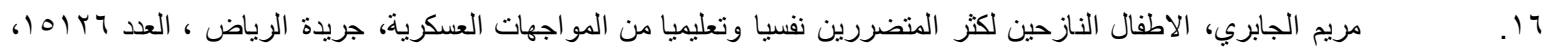

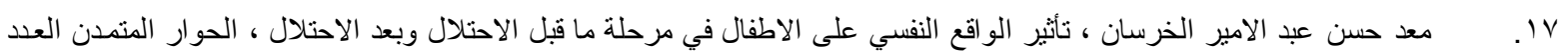
/ r / محور حقوق الانسان

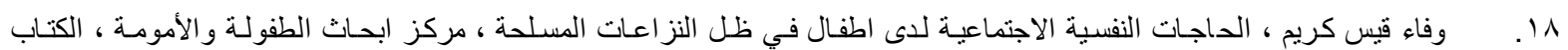

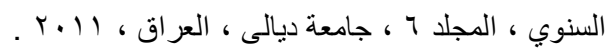

